\title{
TEATRO DE GRUPO: RECONSTRUINDO O TEATRO? ${ }^{1}$
}

André Carreira (Bolsa Produtividade em Pesquisa - CNPq; PPGT; CEART; UDESC)

Palavras-chave: teatro brasileiro; produção teatral; grupo teatral;

A pesquisa sobre teatro de grupo desenvolvida pela equipe do ÁQIS ${ }^{2}$ trata de estabelecer um panorama do teatro de grupo no Brasil, sem a pretensão de criar uma fotografia acabada desse movimento. O foco deste projeto é buscar uma melhor compreensão da atividade desses grupos que têm ampliado sua importância no contexto da cena nacional. Nosso estudo aborda a diversidade de formas e modos de trabalho que constituem a cara mais visível do teatro de grupo. Neste sentido as experiências dos grupos surgidos nos anos 80 e 90, quando o movimento experimentou um incremento significativo, aparecem como elemento fundamental para a reflexão sobre esse modo de produção teatral.

Desde os anos 80, a expressão teatro de grupo começou a circular de forma insistente no ambiente teatral brasileiro fazendo-se, uma década depois, uma idéia comum que sempre aparece vinculada a um teatro alternativo. A referência ao teatro de grupo, movimento que surgiu no processo de democratização do final do século XX, criou o que hoje podemos chamar um campo específico dentro do fazer teatral nacional, que tem vasos comunicantes com movimentos similares na América Latina.

Aparentemente, este movimento estaria conformado por um conjunto de grupos com características estruturais semelhantes que se relacionam com um tipo de projeto teatral bem definido, cujo principal valor residiria exatamente no seu sentido de grupalidade e de alternativa a um teatro que se organizaria a partir de premissas mais próximas aos modos empresariais de produção. Assim, se definiria o terreno do grupal como substrato dos projetos estéticos.

No entanto, o contato com grupos espalhados pelo país ${ }^{3}$ permite afirmar que a idéia de que o teatro de grupo em sua totalidade seja algo que se opõe aos modelos mais empresariais não se coaduna com a realidade observada. Muitos dos grupos que se identificam como parte do movimento do teatro de grupo, têm estruturas de trabalho que mais se assemelham a empresas que ao antigo modelo do grupo amador, ou semi

\footnotetext{
${ }^{1}$ Projeto Teatro de grupo: conformação de modelos de trabalho do ator

${ }^{2}$ Núcleo de pesquisas sobre processos de criação artística, fundado em 1997.

${ }^{3} \mathrm{O}$ projeto do ÁQIS já entrevistou mais de sessenta grupos nas regiões Sul, Sudeste, Centro Oeste.
} 
amador, ou de um grupo independente como os dos anos 60. Modos de trabalho estes cujo elemento central é o coletivo e seu projeto estético e ideológico.

A atividade dos grupos dos anos 60 e 70, que tinha como modelo o Teatro de Arena e o Oficina, definiu procedimentos de trabalho baseados no vigor militante, e exerceu uma forte influência em grupos que trabalharam no período final da ditadura militar. Esse paradigma militante entrou em crise durante o processo de democratização, de tal forma que no início dos anos 90 presenciamos o início de um novo modelo de trabalho grupal. Essa nova geração de grupos, aparentemente carente de modelos de trabalho, dirigiu sua atenção para espaços de experimentação, mas uma das marcas que nos ajuda a compreender essa tendência foi a relação com a própria noção de grupalidade. Isto implica dizer que o grupo, enquanto estrutura organizativa e forma geradora do trabalho criativo, passou a constituir um ponto chave nesse processo.

Um exemplo importante que se relaciona com essa mudança de foco se refere ao fato de que se antes os grupos buscavam sedes para poder estabelecer relações com as comunidades dos bairros - fenômeno característico dos anos 70 em São Paulo -, a sede passou a representar, nos anos 90, o lugar de treinamento e reunião a partir do qual o grupo articula seus projetos espetaculares e pedagógicos. Lugar onde o grupo se funda cotidianamente como unidade criativa. A sede como lugar de referência e como espaço político.

Mas este não é o único elemento que caracteriza o processo do final do século XX. A adoção de processos de produção que incorporam procedimentos do mundo dos negócios é um componente chave neste contexto. Por isso, atualmente, não surpreende a capacidade que alguns os grupos têm de navegar pelos meandros dos processos de financiamento da produção. Isso se dá especialmente a partir do treinamento a que todos os realizadores teatrais foram submetidos pela existência quase onipresente das leis de incentivo a cultura como forma de financiamento da produção.

Hoje em dia a incorporação da lógica da administração se fez algo natural, e por isso já não estranhamos o fato de que grupos teatrais modulem suas práticas a partir de princípios do marketing. Como hábito adquirido no permanente elaborar de projetos, os grupos dialogam com facilidade com uma categoria que no universo dos negócios se chama de razão instrumental. Por isso, 'vender' passou a ser algo muito mais complexo que convidar o público a passar pela bilheteria para adquirir seu ingresso. Vender significa para os grupos construir estratégias amplas de relação com empresas e com órgãos de fomento, através de instrumentos diversos. 
Aqui reside um primeiro aspecto importante para a compreensão do teatro de grupo brasileiro na atualidade: a relação entre criação de espaços de experimentação e as aproximações com modos operacionais do mercado da cultura.

É necessário compreender como essas dinâmicas operam em paralelo com a articulação de discursos coletivos que pretendem construir um espaço alternativo, e que auto reconhecem esse fazer teatral como fala crítica ao sistema hegemônico.

Desde o campo do teatro de grupo observa-se um discurso crítico que reconhece a carência de políticas públicas para um fomento permanente da atividade teatral. $\mathrm{O}$ uso dos mecanismos tais como leis de incentivo à cultura e editais constituem hoje alternativas quase únicas no nosso panorama. Mas os grupos, obrigados a fazerem uso destes instrumentos, se vêm comprometidos com uma trama complexa. O dilema fundamental é que as empresas e os agentes financiadores (FUNARTE, Prefeituras, etc.) através de suas comissões de seleção terminam por estabelecer os parâmetros que permitem acesso aos recursos e assim condicionam a elaboração de projetos.

Neste sentido, é pertinente perguntar se a abundância de projetos que apresentam nos seus argumentos discursos sobre o papel social da proposta, listagens de contrapartidas oferecidas para populações em condição de risco, ou mesmo o planejamento de práticas pedagógicas abertas à comunidade, o fazem porque isso constitui um elemento chave da vida do grupo e de seus processos de criação, ou porque isso pretende atender as expectativas do agente financiador com vistas à aprovação do respectivo projeto para se ter acesso aos recursos disponíveis?

Não é possível discutir o teatro de grupo sem tocar este complicado tema, dado que existe uma forte presença de projetos dessa natureza que estão associados à idéia do grupo como lugar de realização de uma prática teatral distinta, que tem um sítio político mais definido caracterizado como de resistência no contexto nacional.

Outro aspecto que é importante discutir quando falamos de teatro de grupo nasce da percepção que este teatro seria distinto daquele que feito pelos grupos de teatro característico dos anos 60 e 70. Ainda assim, não existem elementos que permitam delimitar um campo homogêneo desse teatro. Algumas características que aparecem de forma insistente quando pensamos os projetos grupais da atualidade remetem à associação entre projetos de criação cênica, articulação de práticas pedagógicas, referência no grupal como mecanismo de autonomia, identidade e resistência, e sobre tudo consciência de que este projeto se distingue de outros procedimentos coletivos pois busca um lugar específico. 
Isto implica dizer que pertencer ao teatro de grupo é antes de mais nada estabelecer um lugar de identidade auto definido pelos próprios grupos. Por isso vemos sob a mesma classificação conjuntos quase familiares, conformados por marido e mulher, que organizam suas produções convocando atores para cada ocasião; grupos com grande quantidade de membros que administram seu trabalho por meio dos procedimentos de cooperativas; grupos cujos membros têm uma associação sem fins de lucros e contratam atores com carteira de trabalho assinada para gestão quase empresarial de suas montagens; grupos que, carecendo inclusive de estrutura jurídica regularizada, trabalham nos moldes dos grupos amadores dos anos 70 como nos tempos da Confederação Nacional de Teatro Amador (CONFENATA); grupos que são reconhecidos como tal pelos pares, mas que estão conformados por um diretor que retêm uma marca e monta espetáculos com diferentes atores segundo as circunstâncias; grupos cuja rotação de componentes faz com que periodicamente sua composição se renove quase completamente.

Ainda existiriam outras formas organizacionais que se situam no terreno do teatro de grupo, mas isso parece não ser fundamental para aqueles que se enquadram neste contexto. Algo os reúne e cria um sentimento de pertencimento que parece suficiente para construir um campo específico dentro da cena brasileira.

O que cimenta este lugar parece ser, especialmente, a idéia de que este conjunto diverso e multifacético reúne majoritariamente aqueles realizadores que se percebem opostos a uma lógica empresarial onde predominaria um agente contratante que regeria a empresa teatral. Mas, existiria tal empresa no conjunto do país? Isso ainda representaria um modelo de hegemonia como foi até os anos 70? Hoje, aquilo que poderia ser considerado um teatro empresarial, a empresa do entretenimento nos palcos, seria aquele teatro associado ao sistema da fama televisiva. Estaria ali a hegemonia à qual se opor?

Não é possível analisar essa situação complexa buscando uma dicotomia radical. Observando a complexidade dos diferentes ambientes teatrais do país, onde convivem realidades muito díspares é possível dizer que não se pode identificar de fato um 'sistema teatral brasileiro unificado'. Se o fazemos não é mais que como instrumento didático. Pensamos um 'teatro brasileiro', mas ele é apenas a somatória de uma enorme quantidade de modos de produção e de uma diversidade na qual convivem modos de produção muito distintos. 
Em todas as zonas do Brasil conseguimos identificar agrupações que reivindicam o lugar do teatro de grupo. Isso implica colocar, aparentemente, em um mesmo lugar um conjunto do Acre, que com recursos da ordem dos vinte mil reais realiza uma produção, e um grupo paulistano que necessita de valores muito superiores para poder montar seus espetáculos, além de contar com o suporte da lei de fomento municipal para sua manutenção permanente. Essa disparidade não ocorre apenas no plano dos recursos financeiros. As diferenças de acesso às informações e as chances de intercâmbio com modelos espetaculares, bem como os modos de produção, constituem finalmente contextos extremadamente distintos no que se refere à própria compreensão do lugar do teatro de grupo. Para aqueles cujo acesso às relações claramente empresariais não passa de uma narrativa distante, o convívio com algumas práticas que sim são do âmbito da relação produtor - empregado, não aparecem como algo a ser criticado. Enquanto nos ambientes onde a distância entre uma prática teatral independente e as relações empresariais (já seja nos palcos ou nos estúdios) é mais próxima, se verifica um reforço do discurso crítico, mas também uma permeabilidade no que se refere à utilização de procedimentos de produção. Um exemplo claro disso pode ser observado no esmero da realização dos books e dos websites dos grupos. $\mathrm{O}$ instrumento do marketing reconhecido como ferramenta inevitável para a sobrevivência é incluída como componente chave da atividade grupal.

A fronteira entre empresa e projeto grupal se estreita de forma extrema. Onde começa o mundo do negócio? A partir de onde quem domina é o projeto artístico? Existe uma fronteira a ser delimitada? Esse dilema é hoje central no contexto do teatro de grupo que se estrutura como discurso alternativo, como fala criativa de resistência, mas que não pode escapar das tensões geradas pelo sistema de financiamento que domina nosso contexto político-cultural.

Dentro desse mundo de tensões ainda é pertinente nos perguntarmos sobre questões técnicas e estéticas. Existe no teatro de grupo um conjunto de procedimentos técnicos ou de projetos estéticos que permitem delimitar um universo com certa especificidade?

Outra vez a idéia de diversidade imperar e dificulta uma delimitação clara. A pesquisadora Rosyane Trotta afirma que vários grupos, tais como o Galpão, Oi Nóis Aqui Travéiz, Imbuaça, Teatro de Anônimo, Quem tem boca é prá gritar, tomaram 
como referência da Antropologia Teatral ${ }^{4}$ a noção de teatro de grupo como um elemento de identidade (2005), como algo que permite perceber um espaço de pertinência bastante delimitado ainda que não restritivo.

A experimentação sobre o trabalho do ator caracterizou o movimento do teatro de grupo no final do século XX. Os grupos Galpão de Belo Horizonte, Oi Nóis Aquí Travéis de Porto Alegre, a Companhia do Latão de São Paulo, Lume de Campinas, Teatro da Vertigem cumpriram um papel central neste período discutindo questões relacionadas com o ator e com as formas do trabalho grupal. Delimitar o trabalho dentro do campo do teatro de grupo significou para estas agrupações definir um âmbito particular no contexto teatral, e assim, estabelecer novas relações com os padrões hegemônicos, construindo mecanismos de sobrevivência e uma nova situação no quadro da cultura nacional.

Um dos pilares do teatro de grupo é uma noção de ator que está centrada na produção de experiências técnicas fundadas na prática do treinamento. A partir disso nascem os elementos chaves das poéticas dos grupos. A idéia de que o ator produz com seu trabalho elementos axiais da dramaturgia dos espetáculos coletivos fez comum o uso da expressão "ator compositor", isto é, um ator que funciona como ponto de ancoragem do trabalho coletivo.

Este novo olhar sobre o ator esteve apoiado na idéia de treinamento, que funcionou como elemento propulsor de um espaço social diferenciado para o ator e para o grupo. $\mathrm{O}$ ator do teatro de grupo que treina cotidianamente seria capaz de reinventarse, e inventar o próprio trabalho grupal, e assim estaria apto a gerar as matrizes para a criação espetacular.

\footnotetext{
${ }^{4}$ Nos anos 80, uma experiência interferiu decisivamente no movimento dos grupos de teatro. Este movimento vivenciou, a partir de 1987, quando da primeira visita de Eugenio Barba organizada pelo Instituto Nacional de Artes Cênicas (INACEN), mudanças importantes no que diz respeito à adoção de novos elementos técnicos. Vários procedimentos que caracterizam o pensamento de Barba e as práticas de grupos como Odin Theatret, Farfa e Táscabile passaram a conformar tema de conversação comum entre nossos grupos, e a influenciar a formulação de modos de trabalho e de organização coletiva. No entanto, a visita de Barba não se deu sem gerar controvérsias, diretores, atores e críticos que participaram do seminário no Rio de Janeiro, discutiram não apenas as idéias de Barba, mas também seus procedimentos pedagógicos. Apesar das controvérsias, a partir deste evento, e das subseqüentes visitas de Barba e dos grupos relacionados com o projeto da Internacional School of Theatrical Anthropology (ISTA), se abriu um diálogo intenso entre as formas e modos de trabalho de vários grupos do Brasil e as referências dos europeus da Antropologia Teatral. Hoje em dia, passados já quase vinte anos dessa visita, podemos dizer que a difusão das idéias de Barba representou uma ruptura - ainda que não central - com a linha histórica do movimento dos grupos brasileiros. O contato com os princípios da Antropologia Teatral contribuiu para instalar no ambiente dos grupos uma série de procedimentos técnicos que se caracterizam pela ênfase no treinamento do ator e nas práticas inter-culturais, bem como na utilização das demonstrações de trabalho e práticas pedagógicas.
} 
À parte os procedimentos e as referências técnicas propostas pela Antropologia Teatral, a idéia de uma disciplina estreitamente relacionada a uma ética e o projeto de um teatro relacionado com o próprio sentido da vida, foi sem lugar a dúvidas, o que mais repercutiu como referência modelar para os grupos no período. Esta nova perspectiva para o trabalho grupal significou a abertura de um novo espaço social e político para diferentes realizadores teatrais.

Com a aparente dissolução da herança das lutas políticas, o lugar de contestação ocupado pelo grupo, característico dos anos 60 e 70, foi substituído por novos elementos de coesão muito mais relacionados com o trabalho específico do teatro. As práticas de pesquisa e preparação técnica, e uma dramaturgia nascida do trabalho criativo do ator constituíram então um ponto de apoio alternativo que se apresentou como uma via possível para a reagrupação dos coletivos sem, no entanto, negar um lugar ético que situa os grupos em relação ao estado das coisas na vida do país.

\section{Referências}

BURNIER, Luis Otávio. Primeiras reflexões sobre o trabalho de Eugenio Barba, In Boletim Informativo INACEN, ano II, 2ª . Série, n. 9, outubro de 1987.

BRANDÃO Tânia. Teatro brasileiro do século 20: as oscilações vertiginosas, In

Revista do patrimônio Brasileiro, n. 29, 2001.

CARREIRA, André. Teatro de rua na Argentina e Brasil dos anos 80 (A Paixão no asfalto). São Paulo, Hucitec. 2007a.

CARREIRA, André Modelo de trabalho grupal no Brasil: dos amadores ao teatro de grupo. (Relatório de pesquisa) Florianópolis. CEART. 2007b.

FERNANDES, Silvia. Grupos Teatrais, anos 70. Campinas, Ed. Unicamp. 2000.

FUSER, Fausto y GUINSBURG, Jacó. A "turma da Polônia" na renovação teatral brasileira presenças e ausências, in Diálogos sobre teatro (org. Armando Sérgio da Silva). Editora Perspectiva, São Paulo, 1992.

GARCIA, Silvana. Teatro da Militância. São Paulo, Perspectiva. 1992.

MICHALSKI, Yan. "Eugenio Barba no Rio: azar e rigor". In Boletim Informativo INACEN, ano II, 2a . Série, n. 9, outubro de 1987.

MILARÉ, Sebastião. Dossiê Renato Vianna - campanhas artísticas, in www.antaprofana.com.br 2005.

Teatro Brasileiro 1918/38: Grupos. Anta Profana. http://www.antaprofana.com.br. 2008.

TROTTA, Rosyane. Eu não sou um realista, in Boletim Informativo INACEN, ano II, $2^{\mathrm{a}}$. Série, n. 9, outubro de 1987.

Teatro de Grupo: utopia e realidade.(no prelo). 2005.

VARGAS, Maria Thereza. Exercícios da livre criação (apresentação), in Grupos Teatrais, anos 70 (FERNANDES, Silvia). Campinas, Ed. Unicamp. 2000. 